\title{
07;08.1
}

\section{Morphology control and optical properties of CdSe nanorods by surface ligands*}

\author{
(C) Zhiyuan Lin ${ }^{1}$, Jinhua $L i^{1}{ }^{1}$, Ke Feng ${ }^{1}$, Yue Wang ${ }^{1}$, Xueying Chu ${ }^{1}$, Siyi $H u^{2}$
}

${ }^{1}$ International Joint Research Center for Nanophotonics and Biophotonics,

Nanophotonics and Biophotonics Key Laboratory of Jilin Province, School of Science,

Changchun University of Science and Technology, Changchun, P.R. China

${ }^{2}$ CAS Key Laboratory of Bio-medical Diagnostics, Suzhou Institute of Biomedical Engineering and Technology, Chinese Academy of Sciences, Suzhou, Jiangsu province, P.R. China

I E-mail: lijh@cust.edu.cn

Поступило в Редакцию 4 фревраля 2019г.

В окончательной редакции 13 мая 2019г.

Принято к публикации 14 мая 2019г.

Исследуются наностержни CdSe, полученные с помощью сольватермического синтеза. Изучено влияние на морфологию этих наностержней поверхностных лигандов при их различном содержании в прекурсорах. Экспериментально показано, что наностержни CdSe с отношением длины к диаметру, уменьшающимся от 4:1 до 2:1 по мере увеличения доли тетрадецилфосфорной кислоты (TDPA) в прекурсоре, демонстрируют красное смещение в спектрах поглощения и фотолюминесценции. Кроме того, с увеличением процентного содержания TDPA наблюдалось улучшение оптической стабильности CdSe. Также обнаружено, что поверхность кристалла, которая не покрыта TDPA, имеет повышенную поверхностную энергию, что приводит к быстрому росту поверхности кристалла и образованию стержнеподобной структуры. Как результат анизотропные эффекты поглощения и флуоресценции, наблюдаемые вдоль длинной оси наностержней, могут найти множество приложений в области оптики и оптических материалов.

Ключевые слова: наностержень CdSe, поверхностные лиганды, контроль морфологии, оптическая стабильность.

* Полный текст статьи опубликован в переводной версии журнала „Письма в ЖТФ“ — „Technical Physics Letters“ (V. 45. N 8). 